\title{
Expression of low and high density lipoprotein receptor genes in human adrenals
}

\author{
Jianqi Liu ${ }^{1,2}$, Päivi Heikkilä ${ }^{1}$, Qing-He Meng ${ }^{3}$, Arvi I Kahri ${ }^{1}$, Matti J Tikkanen ${ }^{3}$ and Raimo Voutilainen ${ }^{1,2}$ \\ ${ }^{1}$ Department of Pathology, PO Box 21, University of Helsinki, FIN-O0014 Helsinki, Finland, ${ }^{2}$ Department of Pediatrics, Kuopio University Hospital, \\ FIN-70210 Kuopio, Finland and ${ }^{3}$ Department of Medicine, Division of Cardiology, Helsinki University Central Hospital, FIN-O0290 Helsinki, Finland \\ (Correspondence should be addressed to Jianqi Liu, Department of Pathology, PO Box 21, University of Helsinki, FIN-OO014 Helsinki, Finland; \\ Email: Jiangi.Liu@helsinki.fi)
}

\begin{abstract}
Corticosteroids are synthesized from cholesterol which may arise from de novo synthesis or from the uptake of low or high density lipoproteins (LDL or HDL). In the present study, we compared the expression and regulation patterns of LDL receptor and CLA-1 (CD36 and LIMPII Analogous-1, an HDL receptor) genes in adult human adrenocortical tissues to shed more light on the relative contribution of LDL and HDL in human adrenal steroidogenesis. By screening 64 normal and pathological adrenal samples by Northern blotting, we found a positive correlation between LDL receptor and CLA-1 mRNA expression in the adrenal tissues $(r=0.547$; spearman rank correlation test $P<0.01)$. Adrenal tissues adjacent to Cushing's adenomas contained consistently less LDL receptor and CLA-1 mRNA than normal adrenals (Mann-Whitney $P<0.05$ ). In primary cultures of normal adrenal cells, accumulation of both LDL receptor and CLA-1 mRNAs was upregulated by ACTH in a dose- and time-dependent manner, with an earlier induction of LDL receptor than CLA-1 mRNA expression. $(\mathrm{Bu})_{2} \mathrm{cAMP}$ also increased the levels of these two mRNAs. Addition of LDL, but not HDL, into the culture medium increased cortisol production in untreated adrenocortical cells. Both LDL and HDL enhanced ACTH-induced cortisol production, with the effect of LDL much stronger than that of HDL. Our data show that LDL receptor and CLA-1's expression is ACTH-dependent and occurs in parallel in human adrenal tissues. LDL rather than HDL may be used as the preferential source of cholesterol for steroidogenesis in human adult adrenocortical cells.
\end{abstract}

European Journal of Endocrinology 142 677-682

\section{Introduction}

Cholesterol is the principal precursor for steroid biosynthesis in steroidogenic tissues. Human adrenocortical cells have normally four sources to provide cholesterol for corticosteroid synthesis: the low density lipoprotein (LDL) receptor pathway, the selective high density lipoprotein (HDL) uptake pathway, de novo cholesterol synthesis, and endogenous cholesteryl ester stores. Previous studies have shown that exogenous cholesterol utilized by human fetal adrenocortical cells is mainly from LDL-cholesterol (1). After binding of LDL to its receptor on adrenal cell membrane, the LDL molecule is internalized and degraded, thereby allowing cholesterol to become available as a substrate for steroid hormone biosynthesis. Although high affinity binding sites for HDL are present on adrenal cell membranes, HDL is not utilized to any significant extent for glucocorticoid production in human fetal adrenals (1). Adequate concentrations of LDL, but not HDL, could suppress 3-hydroxy-3-methylglutaryl coenzyme A reductase, the rate-limiting enzyme for endogenous cholesterol synthesis, in human fetal adrenal cells (2). Adult human adrenocortical cells may also use LDLcholesterol to a greater extent than HDL-cholesterol for steroidogenesis, although HDL-cholesterol can support cortisol production in adult adrenal cells (3).

Recently, mouse SR-BI (scavenger receptor, class B, type I) and its human homolog CLA-1 (CD36 and LIMPII Analogous-1) were identified as HDL receptors mediating selective cholesterol uptake without degradation of the protein component of the HDL (4-6). CLA-1 mRNA is highly expressed in human adrenals, and the accumulation of CLA-1 mRNA is upregulated by adrenocorticotropin (ACTH) in primary cultures of normal human adrenocortical cells (7). These findings raise the possibility that selective uptake of HDLcholesterol through the CLA-1 may be active also in human adrenocortical cells. To gain further insight into the role of LDL and HDL in human adrenal steroidogenesis, we investigated the expression pattern of both LDL receptor and CLA-1 mRNAs in different adrenal tissues 
in vivo, and compared their regulation in primary cultures of normal adrenal cells. In addition, we studied the effects of exogenous LDL and HDL on cortisol production in cultured adrenocortical cells.

\section{Materials and methods}

\section{Tissues}

Normal adrenals were obtained from 12 patients who underwent nephrectomy for kidney tumors. Pathological adrenal glands were obtained during operations performed at the Department of Surgery, Helsinki University Central Hospital. The tissues investigated included adrenocortical adenomas from patients with Cushing's or Conn's syndromes, virilism, or without clinical evidence of steroid overproduction (nonfunctional); nodular and bilateral adrenocortical hyperplasias; adrenocortical carcinomas from patients with Cushing's syndrome, overproduction of aldosterone or virilism; and adrenal glands adjacent to the tumor tissues (Table 1). The histological diagnoses were made by the pathologists, and the clinical diagnoses were confirmed from the hospitals' records of the patients. The research protocol was approved by the Local Ethical Committee.

\section{Cell cultures}

Small pieces of normal and pathological tissues were briefly frozen in liquid nitrogen and then stored at $-70^{\circ} \mathrm{C}$. The remaining tissues were prepared for

Table 1 Relative levels of LDL receptor and CLA-1 mRNAs in normal and pathological adrenal tissues. The values were calculated from scanned autoradiographic signals of Northern blots. Most RNA samples were blotted more than twice and the data are the average values. The data for the LDL receptor and CLA-1 mRNA represent the most abundant $5.3 \mathrm{~kb}$ and $2.9 \mathrm{~kb}$ transcripts respectively. All values were normalized with the respective $28 \mathrm{~S}$ ribosomal RNA signals. Means and ranges (in parentheses) are shown in the table. The means of the RNA values from normal adrenals were adjusted to 100 .

\begin{tabular}{lccc}
\hline Tissue & $\boldsymbol{n}$ & LDL receptor & CLA-1 \\
\hline Normal adrenal & 12 & $100(31-269)$ & $100(66-177)$ \\
Adrenocortical adenoma & & & \\
$\quad$ Cushing's syndrome & 7 & $52(5-187)$ & $89(61-131)$ \\
$\quad$ Adjacent gland & 5 & $20(7-27)$ & $31(12-46)$ \\
$\quad$ Conn's syndrome & 9 & $76(22-150)$ & $96(65-140)$ \\
Adjacent gland & 7 & $157(59-301)$ & $82(63-108)$ \\
$\quad$ Virilizing & 3 & $133(105-150)$ & $55(32-86)$ \\
$\quad$ Adjacent gland & 2 & $50(20-80)$ & $76(67-85)$ \\
$\quad$ Nonfunctional & 3 & $24(7-51)$ & $120(94-138)$ \\
$\quad$ Adjacent gland & 2 & $28(10-45)$ & $63(48-77)$ \\
Adrenocortical hyperplasia & & & \\
$\quad$ Bilateral & 4 & $140(102-186)$ & $129(115-157)$ \\
$\quad$ Nodular & 5 & $82(38-107)$ & $115(109-132)$ \\
Adrenocortical carcinoma & 5 & $87(61-109)$ & $42(8-84)$ \\
\hline
\end{tabular}

primary cultures and treated as described previously (7). Briefly, the adrenal tissues were minced and then dissociated with collagenase-dispase (Boehringer Mannheim, Mannheim, Germany) and deoxyribonuclease-I (Sigma Chemical Co., St Louis, MO, USA). The dispersed cells were cultured in Dulbecco's Modified Eagle's Medium-Ham's F-12 medium (1:1) containing 10\% fetal calf serum. The cultures were maintained with $3 \mathrm{ml}$ of the medium on six-well plastic cell culture dishes (Nunc, Roskilde, Denmark) for 5-10 days. The culture media were refreshed totally every third day without washing. Before experiments, the cells were washed once with PBS, fresh medium was added, and the test agents were added once as single doses in all experiments. For studying the role of exogenous LDL and HDL in cortisol production, the cultured cells were incubated in the above-mentioned medium without serum, or in the lipoprotein-deficient serum (LPDS, 10\%)-supplemented medium. All experiments were performed in triplicate wells and repeated with tissues from different patients. Synthetic ACTH (S-Cortropin) was obtained from N V Organon (Oss, Holland), $(\mathrm{Bu})_{2} \mathrm{cAMP}$ and 12-O-tetradecanoyl phorbol 13-acetate (TPA) from Sigma, and staurosporine from Boehringer Mannheim.

\section{Preparation of LDL and HDL}

Lipoproteins were prepared as described previously (8). Briefly, plasma was prepared from blood samples of normolipidemic subjects by centrifugation $(3000 \mathrm{~g})$. Lipoprotein fractions were separated by sequential ultracentrifugation procedure in a Beckman TL ultracentrifuge (Beckman, Palo Alto, CA, USA). LDL and HDL were isolated at densities of $1.019-1.063 \mathrm{~g} / \mathrm{ml}$ (38000 r.p.m. for $18 \mathrm{~h}$ ) and $1.063-1.210 \mathrm{~g} / \mathrm{ml}$ (50000 r.p.m. for $24 \mathrm{~h}$ ) respectively. The HDL was utilized in this study without further subfractionation. The LDL, HDL and LPDS were used within 3 days with the samples stored in the dark at $4{ }^{\circ} \mathrm{C}$ after preparation. The lipoprotein samples were dialyzed at $4{ }^{\circ} \mathrm{C}$ overnight against PBS before using.

\section{RNA analysis}

Total RNA was isolated from the frozen tissues by ultracentrifugation through a cesium chloride cushion (9). Cytoplasmic RNA was extracted from the cultured cells (10). Northern blotting and hybridizations were performed as described previously (7). The relative intensities of autoradiographic signals were quantified by densitometric scanning. All the RNA data shown here were normalized with the respective $28 \mathrm{~S}$ ribosomal RNA values.

\section{Probes}

The probe for human LDL receptor mRNA was a synthetic oligonucleotide prepared at the Institute of 
Biotechnology, University of Helsinki. The sequence was 5'-CCC ATT GAC ATC GAT GCT TGA GAT GGA GTG-3', corresponding to the nucleotides 57-86 in the exon 12 of the human LDL receptor gene (GenBank Acc. No. L00346) (11). The oligonucleotide probe for human CLA-1 mRNA was described previously (7). The oligonucleotides and mouse ribosomal 28S RNA (used as a loading control) (12) cDNA insert were labeled as described previously (7).

\section{Cortisol measurement}

Cortisol was measured from conditioned cell culture media with the Technicon Immuno 1 System (Bayer Corporation, Tarrytown, NY, USA), performed at the Department of Clinical Chemistry, Helsinki University Central Hospital. This method is a magnetic separation competitive enzyme immunoassay (13). In principle, the cortisol in the medium competes with the analyte cortisol-alkaline phosphatase conjugate for the binding sites on the monoclonal anticortisol antibody-fluorescein isothiocyanate conjugate. The immune complexes formed are then incubated with magnetic particles coated with a monoclonal antifluorescein antibody. After washing, para-nitrophenyl phosphate (pNPP) substrate is added. The pNPP hydrolysis produces a color of an intensity inversely proportional to the concentration of the sample cortisol. The absorbance is measured at $405 \mathrm{~nm}$ to calculate the concentration of cortisol.

\section{Statistics}

The correlations between LDL receptor and CLA-1 mRNA levels in different in vivo samples were analyzed by the Spearman Rank Correlation test. The differences in RNA and cortisol levels were assessed by the MannWhitney test. The level of significance was chosen as $P<0.05$.

\section{Results}

\section{In vivo expression of $L D L$ receptor and $C L A-1$ mRNA}

We screened 64 human adrenal tissues for LDL receptor and CLA-1 mRNA expression with Northern blots and detected abundant expression of these two genes in most adrenal tissues (Fig. 1 and Table 1). Northern blots hybridized with the LDL receptor oligonucleotide probe revealed a predominant transcript of approximately $5.3 \mathrm{~kb}$ in size, in both normal and pathological adrenal tissues. Considerable variations in LDL receptor mRNA levels were evident between different types of adrenal samples or even between individual samples of the same entity. The lowest LDL receptor mRNA levels were measured in the adrenal tissues adjacent to Cushing's adenomas $(P<0.005$, compared with normal adrenals) (Fig. 1 and Table 1). The predominant transcript of CLA-1
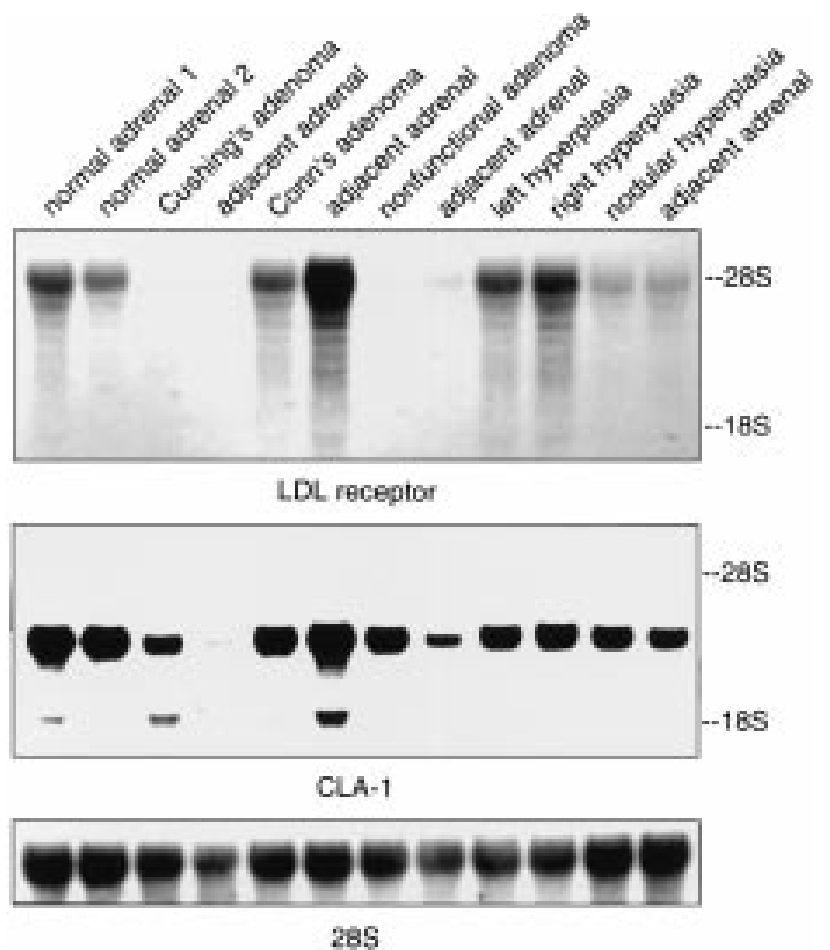

Figure 1 Expression of LDL receptor and CLA-1 mRNAs in normal adrenals, Cushing's, Conn's and nonfunctional adenomas, bilateral and nodular adrenocortical hyperplasias, and the adjacent adrenal tissues. Total RNA was extracted from frozen tissues. The Northern blot was prepared with $20 \mu \mathrm{g}$ of RNA in each lane, and the RNA was transferred onto a nylon membrane. The filter was sequentially hybridized with ${ }^{32} \mathrm{P}$-labeled LDL receptor and CLA-1 oligonucleotide probes and 285 ribosomal RNA CDNA probe. The migration of $28 \mathrm{~S}$ and $18 \mathrm{~S}$ ribosomal RNAs is indicated.

mRNA was $2.9 \mathrm{~kb}$ in size (Fig. 1), as reported previously (7). As in the case of LDL receptor mRNA, the lowest CLA1 mRNA levels were measured in the adrenal tissues adjacent to Cushing's adenomas $(P<0.005$, compared with normal adrenals) (Fig. 1 and Table 1). A positive correlation between LDL receptor and CLA-1 mRNA levels was seen with data pooled from all individual adrenal samples $(r=0.547 ; P<0.01)$.

\section{Regulation of LDL receptor and CLA-1 MRNA expression}

ACTH upregulated both LDL receptor and CLA-1 mRNA accumulation in primary cultures of normal adrenocortical cells in a dose- and time-dependent manner. Although the dose-responsiveness of both LDL receptor and CLA-1 mRNA levels to ACTH was similar after $24 \mathrm{~h}$ treatment (Fig. 2a), the time course after ACTH treatment was different for the accumulation of these two mRNAs (Fig. 3). ACTH had already increased LDL receptor mRNA accumulation at $2 \mathrm{~h}$ of treatment, while CLA-1 mRNA content had not yet changed significantly at this time point (Figs $2 b$ and 3 ). (Bu) $)_{2}$ cAMP increased LDL receptor and CLA-1 mRNA accumulation in 
(b)

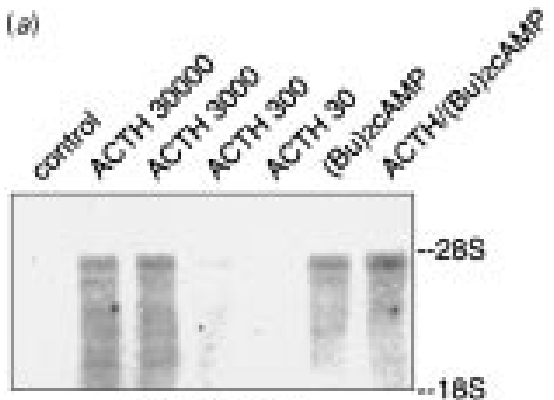

LDL receptor

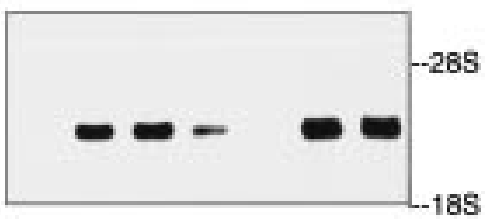

CLA-1

0000

$28 \mathrm{~S}$

(c)

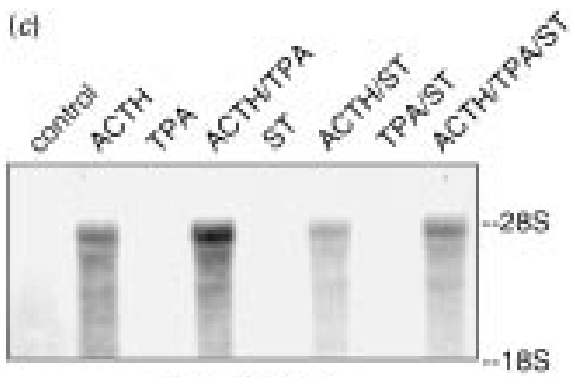

LDL receptor

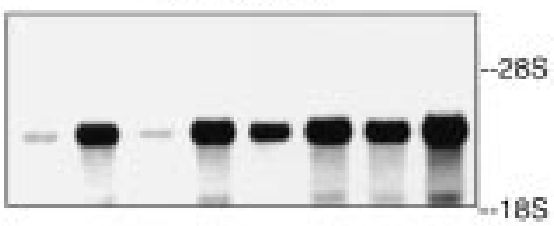

CLA-1

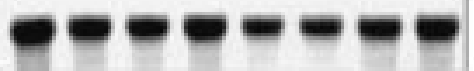

285

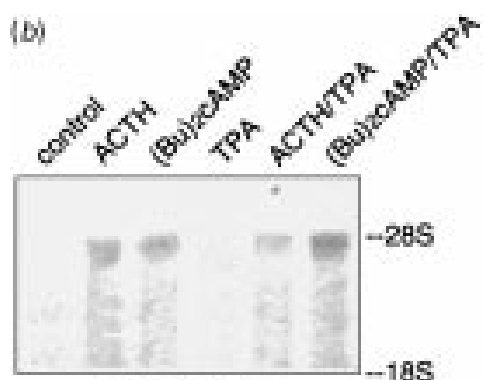

LOL receptor

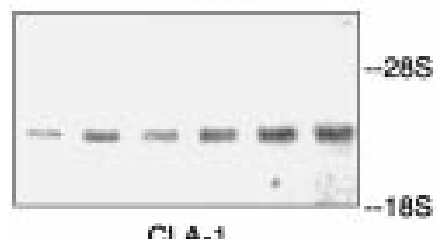

CLA-1

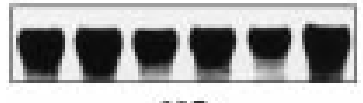

285

[d]

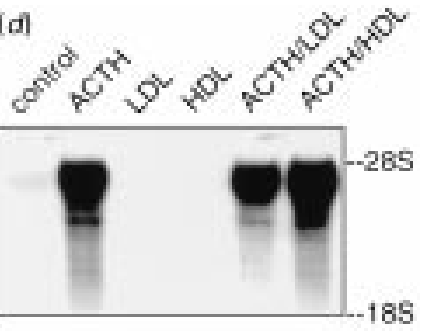

LDL receptor

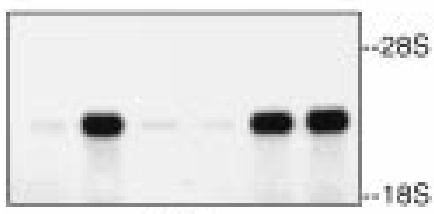

CLA-1

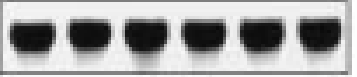

2BS
Figure 2 Regulation of LDL receptor and CLA-1 mRNA accumulation in primary cultures of normal adrenocortical cells. The dispersed cells were allowed to grow for 5-7 days before the agents were added. Cytoplasmic RNA was extracted, and the Northern blots were prepared with $15 \mu \mathrm{g}$ RNA in each lane. The hybridization conditions were the same as in Fig. 1. All experiments were repeated with cells from different patients, and the results were comparable. (a) Dosedependent effects of ACTH (pmol/l) and interaction of $A C T H(30 \mathrm{nmol} / \mathrm{l})$ with

$(\mathrm{Bu})_{2} \mathrm{CAMP}(1 \mathrm{mmol} / \mathrm{l})$ for $24 \mathrm{~h}$. (b) Effects of ACTH $(30 \mathrm{nmol} / \mathrm{l}),(\mathrm{Bu})_{2} \mathrm{CAMP}(1 \mathrm{mmol} / \mathrm{l})$ and TPA $(160 \mathrm{nmol} / \mathrm{l})$ for $2 \mathrm{~h}$. (c) Effects of ACTH $(30 \mathrm{nmol} / \mathrm{l})$, TPA $(160 \mathrm{nmol} / \mathrm{l})$ and staurosporine (ST; $50 \mathrm{nmol} / \mathrm{l})$ for $24 \mathrm{~h}$. (d) Effects of ACTH $(30 \mathrm{nmol} / \mathrm{l}), \mathrm{LDL}(100 \mu \mathrm{g}$ protein/ml) and $\mathrm{HDL}(100 \mu \mathrm{g}$ protein/ml) for $24 \mathrm{~h}$. cultured adrenocortical cells dose-dependently (with the maximal stimulation at the concentration of $1 \mathrm{mmol} / \mathrm{l}$; dose-response not shown), to the same extent as ACTH did. ACTH and $(\mathrm{Bu})_{2} \mathrm{cAMP}$ had no synergetic effect (Fig. $2 a$ ). The changes in LDL receptor and CLA-1 mRNA levels after treatment with the protein kinase $C$ modulator TPA $(160 \mathrm{nmol} / \mathrm{l})$ were not significant in repeated experiments (Fig. $2 b$ and $c$ ). The protein kinase inhibitor staurosporine $(50 \mathrm{nmol} / \mathrm{l})$ increased the accumulation of CLA-1 mRNA, and augmented the stimulatory effect of ACTH on it. However, staurosporine had no significant effect on the basal or ACTHinduced expression of LDL receptor mRNA (Fig. 2c). Both LDL and HDL addition in LPDS-supplemented medium inhibited slightly the accumulation of LDL receptor mRNA $(P<0.05)$, while they had no effect on CLA-1 mRNA content. However, the stimulatory effect of ACTH on LDL receptor and CLA-1 mRNA levels was not significantly affected by either LDL or HDL addition (Fig. 2d). 


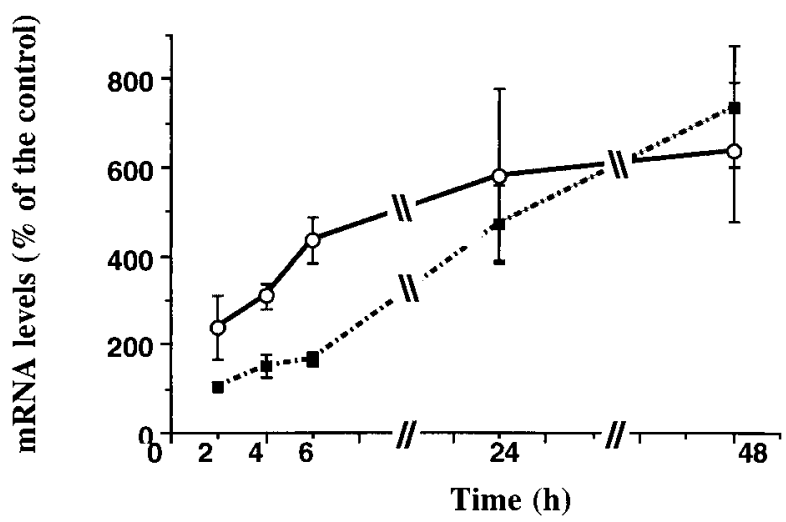

Figure 3 Time-dependent effect of ACTH (30 nmol/I) on LDL receptor (-O-) and CLA-1 (-·- - -) mRNA accumulation. The culture conditions and RNA analysis were the same as in Fig. 2. Each point represents the mean of three experiments (from different patients) \pm range with the control levels at each time point adjusted to 100 .

\section{Regulation of cortisol production}

Both ACTH and $(\mathrm{Bu})_{2} \mathrm{cAMP}$ increased cortisol secretion dose- and time-dependently in serum-supplemented and serum-free media. ACTH increased cortisol secretion about threefold after $2 \mathrm{~h}$ treatment, and up to tenfold after $24 \mathrm{~h}$ treatment, as described previously (14). Some cortisol secretion was maintained in primary cultures with LPDS-supplemented and serum-free media. LDL addition increased cortisol secretion in the absence of ACTH by about $50 \%(P<0.05)$ in LPDS-supplemented medium, while HDL did not (Fig. 4). ACTH increased cortisol secretion about 15-fold in LPDS-supplemented medium $(P<0.05)$ (Fig. 4). Addition of LDL and HDL in LPDS-supplemented medium further increased ACTHinduced cortisol secretion $40 \%$ and $25 \%$ respectively $(P<0.05)$.

\section{Discussion}

Both LDL- and HDL-cholesterol can be used as substrates for the biosynthesis of steroid hormones in human adrenal gland $(1,3)$, but the expression of LDL and HDL receptors or their regulation has not been studied systematically and simultaneously in adult human adrenals. We detected abundant expression of LDL receptor and an HDL receptor (CLA-1) gene in most normal and pathological adrenocortical tissues. Although there was considerable variation in both LDL receptor and CLA-1 mRNA levels in different adrenal tissues, there was a positive correlation between these mRNA species. This suggests that these two lipoprotein receptor genes are regulated through similar pathways in adrenocortical cells. Both LDL receptor and CLA-1 mRNA expression were lower in adrenal tissues adjacent to Cushing's adenomas than in normal adrenals. This alteration is probably due to the reduced serum ACTH concentrations in these patients. Serum ACTH concentrations may be lower than normal also

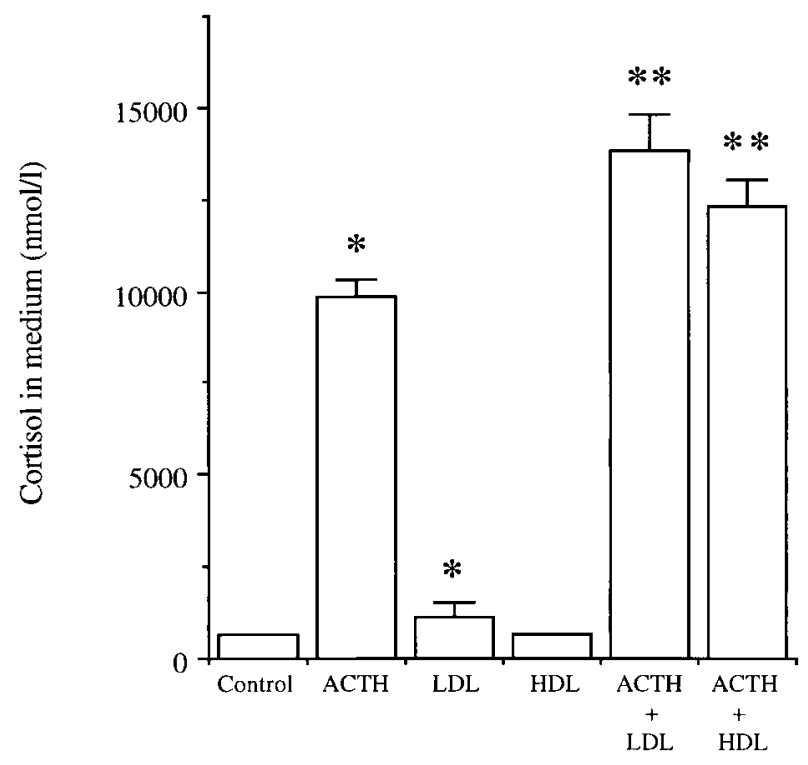

Figure 4 Regulation of cortisol production in cultured normal adrenal cells by ACTH $(30 \mathrm{nmol} / \mathrm{l}), \mathrm{LDL}(100 \mu \mathrm{g}$ protein $/ \mathrm{ml})$ and $\mathrm{HDL}(100 \mu \mathrm{g}$ protein $/ \mathrm{ml}$ ) for $24 \mathrm{~h}$. The culture conditions were the same as in Fig. 2. Each bar represents the mean \pm range from triplicate cultures $\left({ }^{\star} P<0.05\right.$ compared with the control; ${ }^{* \star} P<0.05$ compared with the ACTH group). The experiment was repeated with cells from different patients, and the results were similar.

in some patients with virilizing and nonfunctional adenomas as mild hypercortisolism can often be detected in these patients. This could explain slightly reduced (compared with normal adrenals) LDL receptor and CLA1 mRNA expression in adrenal tissues adjacent to these tumors. Conn's adenomas are usually pure zona glomerulosa derived tumors without glucocorticoid overproduction and suppression of ACTH secretion. Thus it was not unexpected to find LDL receptor and CLA-1 mRNA expression in adrenal tissues adjacent to Conn's adenomas to be equal to normal adrenals.

In primary cultures of normal adrenal cells, the accumulation of both LDL receptor and CLA-1 mRNAs was upregulated by ACTH dose- and time-dependently. However, the induction of LDL receptor mRNA expression appeared much faster than that of CLA-1 mRNA. This is in agreement with our previous experiments with rat adrenocortical cells (15). The stimulatory effect of ACTH on LDL receptor and CLA-1 gene expression may be mediated through similar pathways involving protein kinase A, since the effects of ACTH were mimicked by $(\mathrm{Bu})_{2} \mathrm{cAMP}$ treatment. However, the protein kinase inhibitor staurosporine increased CLA-1 mRNA expression, whereas it had no significant effect on LDL receptor mRNA levels. This suggests that the staurosporine-sensitive protein kinase is differently involved in the regulation of LDL receptor and CLA-1 mRNA expression in human adrenocortical cells.

The cultured adrenocortical cells in LPDS-supplemented medium and in serum-free medium maintained 
cortisol secretion capacity, which was strongly increased by ACTH. This is in agreement with a previous report that biosynthesis of corticosteroids from endogenous cholesterol is active in both untreated and cAMP-stimulated human adult adrenal cells (3). Although there is differential accumulation of cholesterol from LDL and HDL according to ACTH stimulation in bovine adrenocortical cells (16), human adult adrenocortical cells may prefer LDL to HDL as a preferential exogenous cholesterol source for steroidogenesis (3). LDL addition increased basal and ACTHinduced cortisol production and it simultaneously slightly inhibited basal expression of LDL receptor mRNA. However, HDL had no significant effect on basal cortisol secretion, although it enhanced ACTHinduced cortisol production. This could be explained by the lack of functional HDL receptors in non-ACTH treated cells. Interestingly, incubation with HDL also slightly inhibited basal expression of LDL receptor mRNA, whereas it had no effect on the CLA-1 mRNA accumulation. Increased availability of cholesterol due to HDL addition may effectively inhibit LDL gene expression, supporting the hypothesis that the expression of LDL receptor gene is more sensitive than that of CLA-1 gene to changes in cholesterol availability. In human adrenocortical carcinoma NCI-H295 cells, binding and uptake of cholesterol was quantitatively lower from HDL than from LDL, both in basal and in cAMP-stimulated cells (17). Thus, in human adrenocortical cells, LDL receptor pathway may be the main source to provide exogenous cholesterol for corticosteroid biosynthesis, whereas CLA-1 may support or substitute LDL receptor to meet the requirement for cholesterol in exceptional conditions, such as abetalipoproteinemia and homozygous familial hypercholesterolemia $(18,19)$.

In summary, LDL receptor and CLA-1 mRNAs are expressed in parallel in human adrenal tissues. ACTH upregulates the expression of these lipoprotein receptor genes in primary cultures of normal adrenal cells. Both LDL and HDL can be used as substrates for steroidogenesis, but LDL seems to be the preferential source of cholesterol for human adult adrenocortical cells.

\section{Acknowledgements}

Ms Merja Haukka and Ms Eija Heiliö are thanked for their technical assistance. This study was financially supported by the Jalmari and Rauha Ahokas Foundation (to JL), and the Kuopio University Hospital Research Contract No. 5107 (to RV).

\section{References}

1 Carr BR \& Simpson ER. Lipoprotein utilization and cholesterol synthesis by the human fetal adrenal gland. Endocrine Reviews $19812306-325$.

2 Mason JI \& Rainey WE. Steroidogenesis in the human fetal adrenal: a role for cholesterol synthesized de novo. Journal of Clinical Endocrinology and Metabolism 198764 140-147.
3 Higashijima M, Nawata H, Kato K \& Ibayashi H. Studies on lipoprotein and adrenal steroidogenesis: I. Roles of low density lipoprotein- and high density lipoprotein-cholesterol in steroid production in cultured human adrenocortical cells. Endocrinologia Japonica 198734 635-645.

4 Acton S, Rigotti A, Landschulz KT, Xu S, Hobbs HH \& Krieger M. Identification of scavenger receptor SR-BI as a high density lipoprotein receptor. Science 1996271 518-520.

5 Calvo D, Gomez-Coronado D, Lasuncion MA \& Vega MA. CLA-1 is an $85-\mathrm{kD}$ plasma membrane glycoprotein that acts as a highaffinity receptor for both native (HDL, LDL, and VLDL) and modified (OxLDL and AcLDL) lipoproteins. Arteriosclerosis, Thrombosis, and Vascular Biology 199717 2341-2349.

6 Murao K, Terpstra V, Green SR, Kondratenko N, Steinberg D \& Quehenberger O. Characterization of CLA-1, a human homologue of rodent scavenger receptor $\mathrm{BI}$, as a receptor for high density lipoprotein and apoptotic thymocytes. Journal of Biological Chemistry 1997272 17551-17557.

7 Liu J, Voutilainen R, Heikkilä P \& Kahri AI. Ribonucleic acid expression of the CLA-1 gene, a human homolog to mouse high density lipoprotein receptor SR-BI, in human adrenal tumors and cultured adrenal cells. Journal of Clinical Endocrinology and Metabolism 199782 2522-2527.

8 Meng QH, Pajukanta P, Ilmonen M, Schuster H, Schewe CK, Andersson LC et al. Analysis of novel apolipoprotein B mutations using a modified U937 cell line LDL binding assay. Clinica Chimica Acta 1996256 27-36.

9 Chirgwin JM, Przybyla AE, MacDonald RJ \& Rutter WJ. Isolation of biologically active ribonucleic acid from sources enriched in ribonuclaese. Biochemistry 197918 5294-5299.

10 Voutilainen R, Tapanainen J, Chung B, Matteson KJ \& Miller WL. Hormonal regulation of P450scc (20,22-desmolase) and P450c17 (17 $\alpha$-hydroxylase/17,20-lyase) in cultured human granulosa cells. Journal of Clinical Endocrinology and Metabolism $198663202-207$.

11 Yamamoto T, Davis CG, Brown MS, Schneider WJ, Casey ML, Goldstein JL et al. The human LDL receptor: a cysteine-rich protein with multiple Alu sequences in its mRNA. Cell 198439 27-38.

12 Arnheim N. Characterization of mouse ribosomal gene fragments purified by molecular cloning. Gene $1979783-96$.

13 Letellier M, Lévesque A, Daigle F \& Grant A. Performance evaluation of automated immunoassays on the Technicon Immuno I System. Clinical Chemistry 199642 1695-1701.

14 Liu J, Heikkilä P, Kahri AI \& Voutilainen R. Expression of the steroidogenic acute regulatory protein mRNA in adrenal tumors and cultured adrenal cells. Journal of Endocrinology 1996150 43-50.

15 Heikkilä P, Arola J, Liu J \& Kahri AI. ACTH regulates LDL receptor and CLA-1 mRNA in the rat adrenal cortex. Endocrine Research $199824591-593$.

16 Jenkins PJ, Cross TA, Perry LA, Medbak SA, Besser GM \& Clark AJL. The influence of plasma on basal and ACTH-stimulated in vitro adrenocortical steroidogenesis. Journal of Endocrinology 1999 162 155-161.

17 Martin G, Pilon A, Albert C, Valle M, Hum DW, Fruchart JC et al. Comparison of expression and regulation of the high-density lipoprotein receptor SR-BI and the low-density lipoprotein receptor in human adrenocortical carcinoma NCI-H295 cells. European Journal of Biochemistry 1999261 481-491.

18 Illingworth DR, Kenny TA, Connor WE \& Orwoll ES. Corticosteroid production in abetalipoproteinemia: evidence for an impaired response to ACTH. Journal of Laboratory and Clinical Medicine 1982 $100115-126$.

19 Laue L, Hoeg JM, Barnes K, Loriaux DL \& Chrousos GP. The effect of mevinolin on steroidogenesis in patients with defects in the low density lipoprotein receptor pathway. Journal of Clinical Endocrinology and Metabolism 198764 531-535.

Received 5 October 1999

Accepted 3 February 2000 